\title{
Molecular mechanisms of azole resistance in Candida bloodstream isolates
}

Jocelyn Qi-Min Teo ${ }^{1,2}$, Shannon Jing-Yi Lee ${ }^{1}$, Ai-Ling Tan ${ }^{3}$, Robyn Su-May Lim ${ }^{1,8}$, Yiying Cai ${ }^{1,4}$, Tze-Peng Lim ${ }^{1,5,6}$ and Andrea Lay-Hoon Kwa ${ }^{1,6,7^{*}}$ (i)

\begin{abstract}
Background: Antifungal resistance rates are increasing. We investigated the mechanisms of azole resistance of Candida spp. bloodstream isolates obtained from a surveillance study conducted between 2012 and 2015.

Methods: Twenty-six azole non-susceptible Candida spp. clinical isolates were investigated. Antifungal susceptibilities were determined using the Sensititre YeastOne ${ }^{\circledast}$ YO10 panel. The ERG11 gene was amplified and sequenced to identify amino acid polymorphisms, while real-time PCR was utilised to investigate the expression levels of ERG11, CDR1, CDR2 and MDR1.

Results: Azole cross-resistance was detected in all except two isolates. Amino acid substitutions (A114S, Y257H, E266D, and V488I) were observed in all four C. albicans tested. Of the 17 C. tropicalis isolates, eight (47\%) had ERG11 substitutions, of which concurrent observation of Y132F and S154F was the most common. A novel substitution (I166S) was detected in two of the five C. glabrata isolates. Expression levels of the various genes differed between the species but CDR1 and CDR2 overexpression appeared to be more prominent in C. glabrata.
\end{abstract}

Conclusions: There was interplay of various different mechanisms, including mechanisms which were not studied here, responsible for azole resistance in Candida spp in our study.

Keywords: Candida, Antifungal resistance, Genomics

\section{Background}

Candida bloodstream infections are an important healthcare issue known to be associated with high morbidity and mortality. There have been increasing reports of antifungal resistance. We have previously reported decreasing azole susceptibilities in our hospital, particular in Candida tropicalis. More than $20 \%$ of C. tropicalis were non-susceptible to fluconazole [1]. There are various mechanisms mediating azole resistance. It has been suggested that molecular mechanisms such as presence of mutations may be a predictive marker of clinical failure in Candida infections [2]. Whilst this has been established for echinocandin resistance, azole resistance mechanisms are not as well studied, particularly for non-albicans species. Elucidation of these mechanisms is

\footnotetext{
* Correspondence: andrea.kwa.l.h@sgh.com.sg

'Department of Pharmacy, Singapore General Hospital, Blk 8 Level 2, Outram Road, Singapore 169608, Singapore

${ }^{6}$ Singhealth Duke-NUS Medicine Academic Clinical Programme, 8 College

Road, Level 4, Singapore 169857, Singapore

Full list of author information is available at the end of the article
}

crucial to make progress in understanding and treating invasive Candida infections.

\section{Methods}

In this study, we characterised the molecular mechanisms of azole resistance in 26 fluconazole non-susceptible Candida bloodstream isolates. These isolates were identified from a retrospective surveillance study conducted at a major regional tertiary referral hospital between 2012 and 2015 [1]. In brief, non-duplicate Candida bloodstream isolates from all adult inpatients (at least 21 years old) with temporally-related clinical signs and symptoms of infection admitted to the hospital during the study period were included. Antifungal susceptibility testing was performed using Sensititre YeastOne ${ }^{\circ}$ YO10 panel (Trek Diagnostics System, West Sussex, England) according to manufacturer's recommendations. Minimum inhibitory concentrations were interpreted according to the current species-specific clinical breakpoints provided by the Clinical and Laboratory Standards Institute (CLSI)

(c) The Author(s). 2019 Open Access This article is distributed under the terms of the Creative Commons Attribution 4.0 International License (http://creativecommons.org/licenses/by/4.0/), which permits unrestricted use, distribution, and 
M27-S4 document or epidemiological cut-off values (ECV), where CLSI breakpoints were unavailable $[3,4]$. For Candida albicans and C. tropicalis, isolates meeting the susceptible-dose-dependent (SDD) and resistant criteria were included, whereas only resistant Candida glabrata were included in this study. A total of 26 fluconazole non-susceptible isolates [C. albicans - 4/62 (6\%); C. glabrata - 5/82 (6\%); C. tropicalis - 17/78 (22\%); C. parapsilosis - 0/35 (0\%)] were identified from 257 Candida spp. isolates included in the surveillance study.

ERG11, CDR1, CDR2 and MDR1 gene expression were quantified in triplicates using real-time reverse transcription-PCR (RTPCR) with total RNA extracted from exponential-phase yeast peptone dextrose broth cultures on a CFX96 Real-Time PCR Detection System (Bio-Rad, USA). The primers used were adopted from previous publications [5-11], except for C. glabrata CDR1 gene [F - TGGT GTTGCTAATGTCGCCA, R - GTCCCAAGTACTCG
CCACAA] and C. glabrata ERG11 gene [F - CCACCCATT GCACTCTTTGT, R - AGAACGTGGTAGTCCCTTGG]. Quantification of target genes was normalised to the level of $A C T 1$, an endogenous reference gene. Relative gene expression was calculated as the fold change in expression of the isolates compared to the respective ATCC reference strains (C. albicans ATCC 90028, C. glabrata ATCC 2950, C. tropicalis ATCC 750). A fold increase of 3 times was considered to be an overexpression of the target gene. The ERG11 gene was amplified and sequenced to identify amino acid mutations by comparing with reference wild-type GenBank sequences (C. albicans - X13296; C. tropicalis - M23673; C. glabrata - L40389).

\section{Results}

The susceptibility profiles of the isolates are displayed in Table 1. Cross-resistance to all azoles was observed in all isolates except for one C. albicans (CW138) and two C.

Table 1 Molecular characteristics of clinical fluconazole non-susceptible Candida spp. blood isolates

\begin{tabular}{|c|c|c|c|c|c|c|c|c|c|}
\hline \multicolumn{2}{|c|}{ Isolate reference } & \multicolumn{3}{|c|}{$\mathrm{MIC}, \mathrm{ug} / \mathrm{mL}$} & \multicolumn{4}{|c|}{ Gene expression (fold increase) } & \multirow[t]{2}{*}{ Erg11p amino acid substitution(s) } \\
\hline & & $\overline{F L C}$ & VRC & POS & $\overline{E R G 11}$ & CDR1 & $C D R 2$ & MDR1 & \\
\hline \multirow[t]{4}{*}{ C. albicans } & CW138 & 4 (SDD) & $0.12(S)$ & 0.25 (NWT) & 0.41 & 1.60 & 9.01 & 0.18 & $\mathrm{~A} 114 \mathrm{~S}, \mathrm{Y} 257 \mathrm{H}$ \\
\hline & CW357 & $4(S D D)$ & 0.25 (SDD) & 0.25 (NWT) & 0.18 & 1.08 & 5.79 & 0.15 & A114S, Y257H \\
\hline & CW241 & $128(\mathrm{R})$ & $4(\mathrm{R})$ & 1 (NWT) & 0.58 & 4.49 & 122.50 & 141.28 & A114S, Y257H \\
\hline & CW216 & $128(\mathrm{R})$ & $\geq 8(R)$ & $\geq 8$ (NWT) & 0.15 & 0.79 & 3.32 & 4.86 & $E 266 D, \underline{V 488 I}$ \\
\hline \multirow[t]{5}{*}{ C. glabrata } & CW193 & $64(\mathrm{R})$ & 4 (NWT) & $\geq 8$ (NWT) & 0.46 & 23.12 & 23.24 & N.A. & None \\
\hline & CW262 & $64(\mathrm{R})$ & $0.25(\mathrm{WT})$ & $0.5(\mathrm{WT})$ & 1.08 & 22.45 & 7.13 & N.A. & I166S \\
\hline & CW378 & $64(\mathrm{R})$ & 4 (NWT) & $2(\mathrm{WT})$ & 0.56 & 4.02 & 8.08 & N.A. & None \\
\hline & CW088 & $\geq 256(\mathrm{R})$ & 4 (NWT) & $\geq 8$ (NWT) & 1.10 & 19.78 & 14.55 & N.A. & None \\
\hline & CW404 & $\geq 256(R)$ & $\geq 8$ (NWT) & $\geq 8$ (NWT) & 0.29 & 18.70 & 6.92 & N.A. & I166S \\
\hline \multirow[t]{17}{*}{ C. tropicalis } & CW190 & $4(\mathrm{SDD})$ & 0.25 (SDD) & 0.5 (NWT) & 0.39 & 6.11 & N.A. & 0.47 & None \\
\hline & CW219 & $4(\mathrm{SDD})$ & $0.5(\mathrm{R})$ & 0.5 (NWT) & 0.95 & 1.56 & N.A. & 0.77 & None \\
\hline & CW361 & 4 (SDD) & $0.5(\mathrm{R})$ & 0.25 (NWT) & 2.38 & 0.27 & N.A. & 0.01 & None \\
\hline & CW395 & $4(\mathrm{SDD})$ & $0.5(R)$ & 0.5 (NWT) & 0.45 & 0.63 & N.A. & 3.27 & None \\
\hline & CW071 & $8(\mathrm{R})$ & 0.25 (SDD) & 0.5 (NWT) & 0.11 & 1.28 & N.A. & 30.53 & None \\
\hline & CW018 & $16(\mathrm{R})$ & 0.25 (SDD) & 0.25 (NWT) & 0.61 & 2.75 & N.A. & 23.42 & Y132F, S154F \\
\hline & CW107 & $16(\mathrm{R})$ & $1(\mathrm{R})$ & 0.5 (NWT) & 0.36 & 0.09 & N.A. & 7.12 & $\underline{\mathrm{Y} 132 \mathrm{~F}}, \underline{\mathrm{S} 154 \mathrm{~F}}$ \\
\hline & CW178 & $16(\mathrm{R})$ & $0.5(\mathrm{R})$ & 1 (NWT) & 2.83 & 3.81 & N.A. & 0.64 & None \\
\hline & CW385 & $16(\mathrm{R})$ & $0.5(\mathrm{R})$ & 1 (NWT) & 0.12 & 4.43 & N.A. & 2.93 & None \\
\hline & CW263 & $64(\mathrm{R})$ & $4(\mathrm{R})$ & 0.12 (NWT) & 4.45 & 1.95 & N.A. & 1.44 & Y132F, S154F \\
\hline & CW386 & $128(\mathrm{R})$ & $2(\mathrm{R})$ & 4 (NWT) & 1.36 & 0.68 & N.A. & 1.33 & None \\
\hline & CW065 & $\geq 256(R)$ & $4(\mathrm{R})$ & 0.5 (NWT) & 1.04 & 1.30 & N.A. & 23.07 & Y132F, S154F \\
\hline & CW067 & $\geq 256(R)$ & $\geq 8(R)$ & 1 (NWT) & 0.11 & 0.93 & N.A. & 7.04 & Y132F, S154F, F145 L \\
\hline & CW192 & $\geq 256(R)$ & $\geq 8(\mathrm{R})$ & 1 (NWT) & 1.36 & 0.76 & N.A. & 0.52 & Y132F, S154F \\
\hline & CW242 & $\geq 256(\mathrm{R})$ & $\geq 8$ (R) & 1 (NWT) & 0.50 & 6.10 & N.A. & 1.21 & $\underline{\mathrm{Y} 132 \mathrm{~F}}, \underline{\mathrm{S} 154 \mathrm{~F}}$ \\
\hline & CW266 & $\geq 256(R)$ & $4(\mathrm{R})$ & 0.25 (NWT) & 0.27 & 10.08 & N.A. & 1.59 & None \\
\hline & CW271 & $\geq 256(\mathrm{R})$ & $\geq 8(\mathrm{R})$ & 1 (NWT) & 7.47 & 1.30 & N.A. & 0.31 & Y132F, S154F \\
\hline
\end{tabular}


glabrata (CW262 and CW378) isolates. All isolates retained susceptibility to other anti-fungals including anidulafungin, caspofungin, micafungin and amphotericin B (data not shown). In C. albicans, all isolates showed non-synonymous homozygous ERG11 substitutions which included three distinct substitutions (A114S, Y257H and E266D). I166S substitutions were detected in two of the six C. glabrata isolates. Of the 17 C. tropicalis isolates, eight (47\%) had ERG11 substitutions. The most common substitutions were the concurrent observation of Y132F and S154F, which occurred primarily in resistant isolates with fluconazole MICs $\geq 8 \mu \mathrm{g} / \mathrm{mL}$. Only two of the eight ERG11 substitutions were homozygous, and there does not appear to be any correlation of the type of substitutions with MICs. The ERG11 substitutions observed in all of the Candida spp. have been previously reported in literature except for I166S.

Among the different gene targets, it appeared that ERG11 expression levels were mostly similar compared to the respective wild-type reference strains. CDR2 expression was consistently elevated in fluconazole non-susceptible $C$. albicans. In the two resistant isolates with MIC $128 \mu \mathrm{g} / \mathrm{mL}, M D R 1$ was also up-regulated. CDR1 and CDR2 co-expression was observed in all $C$. glabrata isolates. Gene overexpression was not consistent among C. tropicalis isolates - there were five isolates with CDR1 overexpression and six isolates with MDR1 overexpression. All C. tropicalis isolates only had overexpression of a single gene target. Interestingly, there were three C. tropicalis isolates with no ERG11 mutations or any gene up-regulation.

\section{Discussion}

In this study, we evaluated the molecular mechanisms associated with azole resistance in various Candida species in our institution. Identification of antifungal susceptibilities through phenotypic methods such as MIC testing is often limited by the length of time required. Furthermore, current fungal MIC breakpoint interpretations are not supported by robust clinical data and are not predictive of clinical success/failure. Therefore, there is interest in identifying genotypic markers which could be rapidly identified for use in clinical prediction. Various previous studies have investigated different mechanisms of azole resistance in Candida species [5, 12-14]. Some of these studies have identified key ERG11 substitutions which are associated with azole resistance e.g. Y132F, S154F [8, 15] and suggested that these mutations could be potential predictive markers of azole resistance.

In our context, it appeared that there was an interplay of various different mechanisms, including mechanisms which were not studied here, responsible for azole resistance in Candida spp. ERG11 mutations were commonly detected in C. albicans, whereas the role of overexpression of azoles efflux pumps appeared to be more prominent in C. albicans (CDR1) and C. glabrata (CDR1, CDR2). In C. tropicalis, presence of Y132F and S154F substitutions was unable to explain the mechanisms of majority of our isolates. Less than half of the azole-resistant C. tropicalis harboured these amino acid substitutions. This was in contrast to the high frequency identified in another local study where $>90 \%$ of the isolates had Y132F and S154F substitutions [15]. Likewise, in another study, these mutations accounted for $95 \%$ of the fluconazole-resistant $C$. tropicalis [16].

Our study was limited by the small sample size although we had included all azole-resistant bloodstream isolates between 2012 and 2015. In addition, we did not perform further functional verification of the ERG11 mutations and homology modelling experiments, therefore the clinical significance of I166S amino acid substitution in C. glabrata remains to be validated.

\section{Conclusions}

In conclusion, our results indicated that the mechanisms mediating azole resistance in our isolates are heterogeneous. There were isolates with unidentified resistance mechanisms warranting further exploration. Moving ahead, the use of more advanced molecular technologies such as next-generation sequencing might be considered for an in-depth molecular characterisation of azole-resistant Candida spp to aid the identification of potential resistance markers.

\section{Abbreviations \\ ATCC: American Type Culture Collection; CLSI: Clinical and Laboratory Standards Institute; ECV: Epidemiological cut-off values; PCR: Polymerase chain reaction; RTPCR: Real-time reverse-transcription polymerase chain reaction}

\section{Acknowledgements}

The authors acknowledge the excellent assistance of lab members of the Microbiology Lab, in particular Ms. Tan Mei Gie, and staff of the Pharmacy Research Lab, Singapore General Hospital, in the collection of the isolates. This study was presented in part at the 27th European Congress of Clinical Microbiology \& Infectious Diseases, Vienna, Austria, 22nd - 25th April 2017 and the ASM Microbe 2017 meeting, New Orleans, USA, 1st - 5th June 2017.

\section{Funding}

This study was funded by grants from National Medical Research Council (NMRC/TA/0025/2013 and NMRC/CG/016/2013); and Pfizer Inc. (WS2347894). The study was also supported in part by Astellas Pharma Singapore Pte Ltd. with materials donation. The funders had no involvement in the study design, in the collection, analysis and interpretation of the data, or in the decision to submit the article for publication.

Availability of data and materials

Please contact corresponding author for data requests.

Authors' contributions

JQT, SJL, RSL, YC, TPL and ALT participated in the microbiological and/or molecular experiments. JQT and ALK conceived the study, interpreted the results, revised the manuscript and wrote the manuscript. All authors read and approved the final manuscript. 


\section{Ethics approval and consent to participate}

The research protocol was approved by the Singhealth Centralised Institutional Review Board (2013/987/D). Informed consent was waived in view of retrospective nature of study.

\section{Consent for publication}

Not applicable.

\section{Competing interests}

The authors declare that they have no competing interests.

\section{Publisher's Note}

Springer Nature remains neutral with regard to jurisdictional claims in published maps and institutional affiliations.

\section{Author details}

'Department of Pharmacy, Singapore General Hospital, Blk 8 Level 2, Outram Road, Singapore 169608, Singapore. ${ }^{2}$ Saw Swee Hock School of Public Health, National University of Singapore, 12 Science Drive 2, \#10-01, Singapore 117549, Singapore. ${ }^{3}$ Department of Microbiology, Singapore General Hospital, Outram Road, Singapore 169608, Singapore. ${ }^{4}$ Department of Pharmacy, National University of Singapore, 18 Science Drive 4, Singapore 117543, Singapore. ${ }^{5}$ Singhealth Duke-NUS Pathology Academic Clinical Programme, 8 College Road, Level 4, Singapore 169857, Singapore. ${ }^{6}$ Singhealth Duke-NUS Medicine Academic Clinical Programme, 8 College Road, Level 4, Singapore 169857, Singapore. 'Emerging Infectious Diseases, Duke-National University of Singapore Medical School, 8 College Rd, Singapore 169857, Singapore. ${ }^{8}$ Present address: Program in Health Services and Systems Research, Duke-National University of Singapore Medical School, 8 College Rd, Singapore 169857, Singapore.

Received: 5 March 2018 Accepted: 2 January 2019

Published online: 17 January 2019

\section{References}

1. Teo JQ, Candra SR, Lee SJ, Chia SY, Leck H, Tan AL, Neo HP, Leow KW, Cai Y, Ee RP, et al. Candidemia in a major regional tertiary referral hospital epidemiology, practice patterns and outcomes. Antimicrob Resist Infect Control. 2017;6:27.

2. Shields RK, Nguyen MH, Press EG, Kwa AL, Cheng S, Du C, Clancy CJ. The presence of an FKS mutation rather than MIC is an independent risk factor for failure of echinocandin therapy among patients with invasive candidiasis due to Candida glabrata. Antimicrob Agents Chemother. 2012;56(9):4862-9.

3. CLSI. Reference Method for Broth Dilution Antifungal Susceptibility Testing of Yeasts; Fourth Informational Supplement. CLSI document M27-S4. Wayne: Clinical and Laboratory Standards Institute; 2012.

4. Canton E, Peman J, Iniguez C, Hervas D, Lopez-Hontangas JL, Pina-Vaz C, Camarena JJ, Campos-Herrero I, Garcia-Garcia I, Garcia-Tapia AM, et al. Epidemiological cutoff values for fluconazole, itraconazole, posaconazole, and voriconazole for six Candida species as determined by the colorimetric Sensititre YeastOne method. J Clin Microbiol. 2013;51(8):2691-5.

5. Vandeputte P, Larcher G, Berges T, Renier G, Chabasse D, Bouchara JP. Mechanisms of azole resistance in a clinical isolate of Candida tropicalis. Antimicrob Agents Chemother. 2005;49(11):4608-15.

6. Chau AS, Mendrick CA, Sabatelli FJ, Loebenberg D, McNicholas PM. Application of real-time quantitative PCR to molecular analysis of Candida albicans strains exhibiting reduced susceptibility to azoles. Antimicrob Agents Chemother. 2004:48(6):2124-31.

7. Mane A, Vidhate P, Kusro C, Waman V, Saxena V, Kulkarni-Kale U, Risbud A. Molecular mechanisms associated with fluconazole resistance in clinical Candida albicans isolates from India. Mycoses. 2016;59(2):93-100.

8. Jiang C, Dong D, Yu B, Cai G, Wang X, Ji Y, Peng Y. Mechanisms of azole resistance in 52 clinical isolates of Candida tropicalis in China. J Antimicrob Chemother. 2013;68(4):778-85.

9. Caudle KE, Barker KS, Wiederhold NP, Xu L, Homayouni R, Rogers PD. Genomewide expression profile analysis of the Candida glabrata Pdr 1 regulon. Eukaryot Cell. 2011;10(3):373-83.

10. Li QQ, Skinner J, Bennett JE. Evaluation of reference genes for real-time quantitative PCR studies in Candida glabrata following azole treatment. BMC Mol Biol. 2012;13:22.
11. Chen LM, Xu YH, Zhou CL, Zhao J, Li CY, Wang R. Overexpression of CDR1 and CDR2 genes plays an important role in fluconazole resistance in Candida albicans with G487T and T916C mutations. J Int Med Res. 2010; 38(2):536-45.

12. Henry KW, Nickels JT, Edlind TD. Upregulation of ERG genes in Candida species by azoles and other sterol biosynthesis inhibitors. Antimicrob Agents Chemother. 2000;44(10):2693-700.

13. Sanguinetti M, Posteraro B, Fiori B, Ranno S, Torelli R, Fadda G. Mechanisms of azole resistance in clinical isolates of Candida glabrata collected during a hospital survey of antifungal resistance. Antimicrob Agents Chemother. 2005:49(2):668-79.

14. Eddouzi J, Parker JE, Vale-Silva LA, Coste A, Ischer F, Kelly S, Manai M, Sanglard D. Molecular mechanisms of drug resistance in clinical Candida species isolated from Tunisian hospitals. Antimicrob Agents Chemother. 2013;57(7):3182-93.

15. Chew KL, Cheng JWS, Jureen R, Lin RTP, Teo JWP. ERG11 mutations are associated with high-level azole resistance in clinical Candida tropicalis isolates, a Singapore study. Mycoscience. 2017;58(2):111-5.

16. Fan X, Xiao M, Zhang D, Huang JJ, Wang H, Hou X, Zhang L, Kong F, Chen SC, Tong ZH, et al. Molecular mechanisms of azole resistance in Candida tropicalis isolates causing invasive candidiasis in China. Clin Microbiol Infect. 2018. https://doi.org/10.1016/j.cmi.2018.11.007. Epub ahead of print.

\section{Ready to submit your research? Choose BMC and benefit from:}

- fast, convenient online submission

- thorough peer review by experienced researchers in your field

- rapid publication on acceptance

- support for research data, including large and complex data types

- gold Open Access which fosters wider collaboration and increased citations

- maximum visibility for your research: over $100 \mathrm{M}$ website views per year

At BMC, research is always in progress.

Learn more biomedcentral.com/submissions 